Article

\title{
Modulation of ATP8B1 gene expression in colorectal cancer cells suggest its role as a tumor suppressor
}

Saleh Althenayyan ${ }^{\# 1,2}$, Amal AlGhamdi ${ }^{\# 1,2}$, Mohammed H AlMuhanna ${ }^{1,2}$, Esra Hawsa ${ }^{1,2}$, Dalal Aldeghaither ${ }^{5,1}$, Jahangir Iqbal ${ }^{3}$, Sameer Mohammad ${ }^{4}$ and Mohammad Azhar Aziz ${ }^{1 *}$ \#Authors contributed equally

${ }^{1}$ King Abdullah International Medical Research Center, Colorectal Cancer Research Program, Department of Cellular therapy and cancer research, Riyadh, 11481, Saudi Arabia

${ }^{2}$ King Saud Bin Abdulaziz University for Health Sciences, Riyadh, 11481, Saudi Arabia

${ }^{3}$ King Abdullah International Medical Research Center (KAIMRC), King Saud bin Abdulaziz University for Health Sciences, King Abdulaziz Medical City Hospital, Ministry of National Guard Health Affairs, Al Hasa, 31982, Saudi Arabia.

${ }^{4}$ King Abdullah International Medical Research Center, Department of Experimental Medicine, Riyadh, 11481, Saudi Arabia

${ }^{5}$ King Saud Bin Abdulaziz University for Health Sciences, College of Science and Health Professions, Department of Basic Science. Riyadh, 11481, Saudi Arabia

* Corresponding Author:

Mohammad A. Aziz, PhD

King Abdullah International Medical Research Center (KAIMRC)

King Saud Bin Abdulaziz University for Health Sciences

King Abdulaziz Medical City

Ministry of National Guard Health Affairs

PO box 3660 Riyadh 11481, Saudi Arabia

Mail Code 1515

Tel. No.: +966 114294582

Email: $\underline{\text { azizmo@ngha.med.sa, maa32@ case.edu }}$ 
Simple Summary: Colorectal cancer development undergoes molecular changes that define different stages. Loss of tumor suppressor genes contribute in this progression. A better understanding of these genes is crucial to develop therapeutic strategies. Discovery and characterization of novel tumor suppressor genes is therefore highly pertinent. From our previous studies, we discovered a possible novel tumor suppressor gene which is found on long arm of chromosome 18 (18q). We modified the expression levels of this gene in colorectal cancer cell lines and studied the effect on cell growth and proliferation. Downregulated level of this gene was associated with increased rate of proliferation whereas overexpression resulted in slower growth. We suggest possible involvement of this novel gene in fatty acid metabolism and lipid transport.

Abstract: Sporadic colorectal cancer (CRC) develops through distinct molecular events. Loss of $18 \mathrm{q}$ chromosome is a conspicuous event in the progression of adenoma to carcinoma. There is limited information regarding the molecular effectors of this event. Earlier, we had reported ATP8B1 as a novel gene associated with CRC. ATP8B1 belongs to the family of P-type ATPases (P4 ATPase) that primarily function to facilitate the translocation of phospholipids. In this study, we attempt to implicate ATP8B1 gene located on chromosome $18 \mathrm{q}$ as a tumor suppressor gene. We studied indigenous patient data and confirmed the reduced expression of ATP8B1 in tumor samples. CRC cell lines were engineered with reduced and enhanced levels of ATP8B1 which provided a tool to study its role on cancer progression. Forced reduction of ATP8B1 expression either by CRISPR/Cas9 or shRNA was associated with increased growth and proliferation of CRC cell line - HT29. In contrast, overexpression of ATP8B1 resulted in reduced growth and proliferation of SW480 cell line. We generated a network of genes that are downstream of ATP8B1. Further, we provide predicted effect of modulation of ATP8B1 levels on this network and possible effect on fatty acid metabolism related genes. These results provide evidence in support of ATP8B1 being a tumor suppressor that may affect fatty acid metabolism in CRC.

Keywords: Colorectal cancer, flippase, ion transporter, tumor suppressor gene, chromosome 18q, lipid transport

1. Introduction

GLOBOCAN 2018 reports colorectal cancer (CRC) to be the fourth highest incidence and third highest killing type of cancer in the world. CRC is known to initiate and progress through pathways that involve inactivation of tumor suppressor genes and activation of oncogenes. These pathways have been classified as chromosomal instability (CIN), microsatellite instable (MSI), and $\mathrm{CpG}$ island methylator phenotype (CIMP) [1]. CIN pathway accounts for most of the CRC cases (85\%) [2]. This pathway is characterized by high rate of gains and losses of large portions of chromosomes. Loss of $18 \mathrm{q}$ chromosome is a well-known event in the initiation of CRC along with other changes in APC, KRAS and TP53 genes. The mechanism by which loss of chromosome $18 \mathrm{q}$ contributes towards CRC is not fully known. DCC and SMAD4 genes located at 18q are possible mediators in CRC 
progression. There is a quest to better understand the molecular determinants of CRC progression that can serve as biomarkers and therapeutic targets.

Membrane proteins are attractive drug targets owing to their role as transporters and interactors with cell environment [3]. CD95, a membrane protein, was found to be associated with colorectal cancer as well as breast and prostate cancer [4-6]. Several other membrane proteins are known to be associated with different types of cancer with diverse functions. Among membrane proteins, members of adenosine triphosphatase (ATPase) family proteins have been implicated in colorectal cancer [7-9] and have been targeted for therapeutic purpose. There are five different types of ATPase viz., F, V, A, P and E based on functional differences. P-type ATPases are involved in transporting various types of molecules including ions and phospholipids [10]. P4-type ATPases have also been suggested as targets for cancer therapeutics [11]. ATP11A was reported as a predictive marker for CRC metastasis [12]. Research efforts are directed towards understanding the functional aspects of ATPases in relation to the onset of these diseases. Role of Secretory Pathway Calcium ATPase 1 (SPCA1) in breast cancer had been reported [6] but evidence in other types of cancer is not established. ATPase, Class I, Type 8B, Member 1 (ATP8B1) gene codes for a P4-type ATPase that has been associated with many pathological conditions including hepatic cholestasis [13,14] and pancreatitis [15]. ATP8B1 alternative splicing has been used in suggesting therapeutic strategies for ATP8B1 deficiency in hepatic cholestasis [16]. Germline mutations in ATP8B1 gene has been found in progressive familial intrahepatic cholestasis Type 1 [17-19]. Mutations in ATP8B1 gene were also reported in several types of cancer [20-22]. However, the expression levels of ATP8B1 gene have not been well studied.

The advent of high resolution technologies like microarray and next generation sequencing has enabled us to probe the chromosomal instability at higher resolution in more detail. Previously, our Cytoscan HD array based data showed copy number loss in the ATP8B1 gene locus [23]. ATP8B1 gene was ranked high according to Genomic Identification of Significant Targets in Cancer (GISTIC) score (measure of significance at cytogenetic level). Exon array studies suggested significant downregulation of this gene in CRC samples [24]. ATP8B1 was also suggested as a favorable prognostic biomarker in CRC [25]. In this report, 
we further characterize the expression level of ATP8B1 in colon cancer cell lines as well as patient samples. We provide evidence that suggests ATP8B1 as a tumor suppressor gene that may affect fatty acid metabolism.

2. Results

\subsection{ATP8B1 is down regulated in colorectal cancer}

Previously, we used cytogenetic and exon microarrays to study chromosomal aberrations and gene expression changes in tumor-normal paired samples from CRC patients. ATP8B1 was found to be significantly associated with CRC in this indigenous dataset [23,24]. We analyzed the expression of ATP8B1 gene in CRC patient samples using exon microarray data from matched tumor-normal samples. ATP8B1 gene expression was significantly down regulated in patient tumor samples (p-value <0.0001) (Figure 1A). Further we carried out qRT-PCR based assays on available patient samples $(n=11)$ to validate these results (Figure 1B). We also analyzed the expression of ATP8B1 in colorectal cancer (DLD1, HT29, SW480, SW620, HCT8, HCT116) and normal colon (CCD841) cell lines. Gene expression levels varied among the cell lines with HT29 and SW480 showing the highest and lowest values, respectively (Figure 1C). The heterogeneity of gene expression was also evident at the protein level in these cell lines (Figure 1D). 


\section{Figure 1}

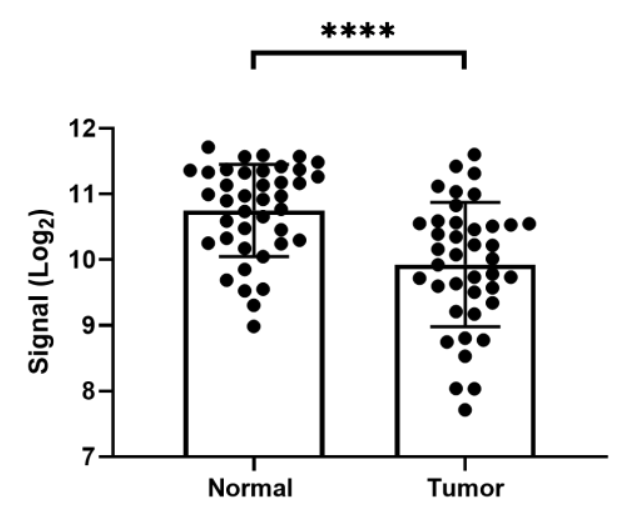

A

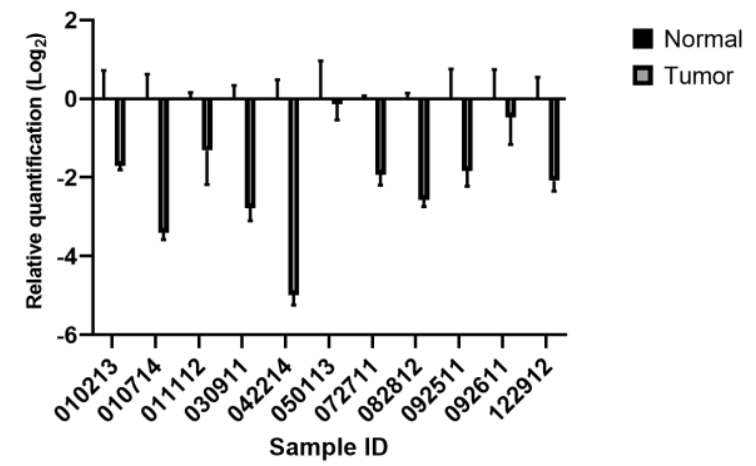

B

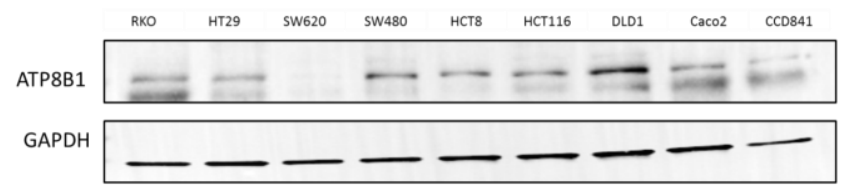

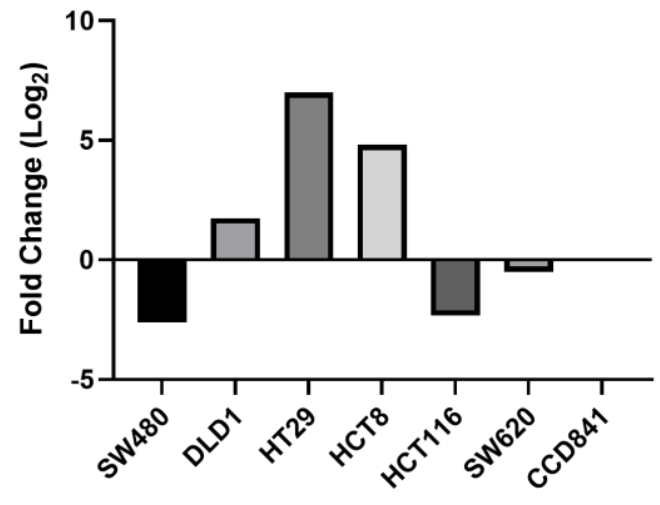

Cell line

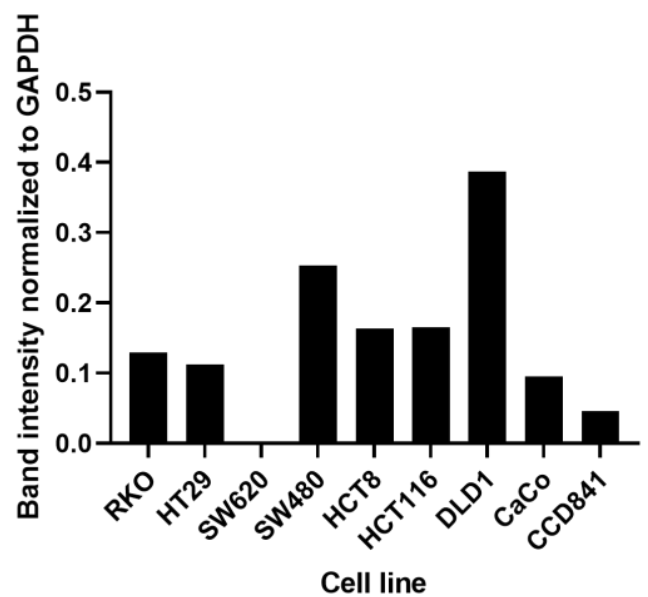

D

\section{C}

\section{Figure 1: ATP8B1 expression in colorectal cancer patients}

A: Exon microarray data from 41 patients shows significant downregulation of ATP8B1 in tumor as compared to adjacent normal tissue. B: Eleven of these patient samples were further analyzed for ATP8B1 gene expression using Taqman assays. Significant downregulation of ATP8B1 gene was observed in all patients. C: Six available colorectal cancer cell lines were analyzed for ATP8B1 gene expression in comparison to normal colon cells (CCD841) using qRT-PCR. D: Protein levels in colorectal cancer cell lines were measured which reflected the heterogeneity at protein level. 
Short hairpin RNA mediated downregulation of ATP8B1 in HT29 cells

HT29 cells with relatively higher expression of ATP8B1 were used for down regulating the gene expression in a stable manner using Short hairpin RNA (shRNA) based RNAi technology. After selection of stable colonies, we were able to observe $44 \%$ down regulation (Figure 2A). Western blot analysis confirmed the effect of downregulation at protein level with $50 \%$ reduced levels in shRNA transfected cells (Figure 2B). Further, we analyzed the rate of proliferation of these cells in real time. There was significant increase in rate of cell proliferation as measured at $24 \mathrm{~h}(54 \%)$ and $48 \mathrm{~h}(67 \%)$ time points (Figure 2C). Cell viability assay further confirmed the results with increased viability for cells with reduced ATP8B1 expression (Figure 2D). 


\section{Figure 2}

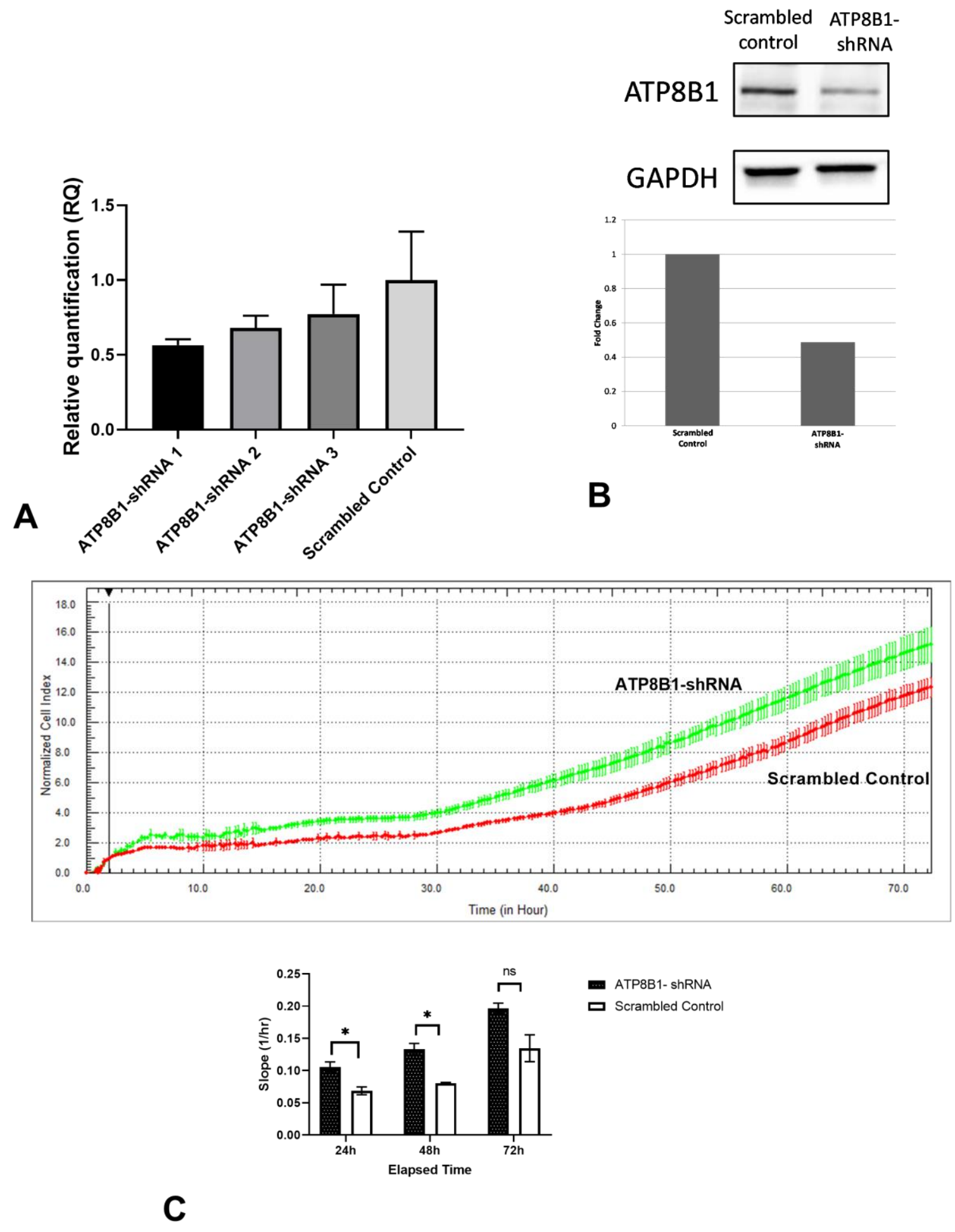




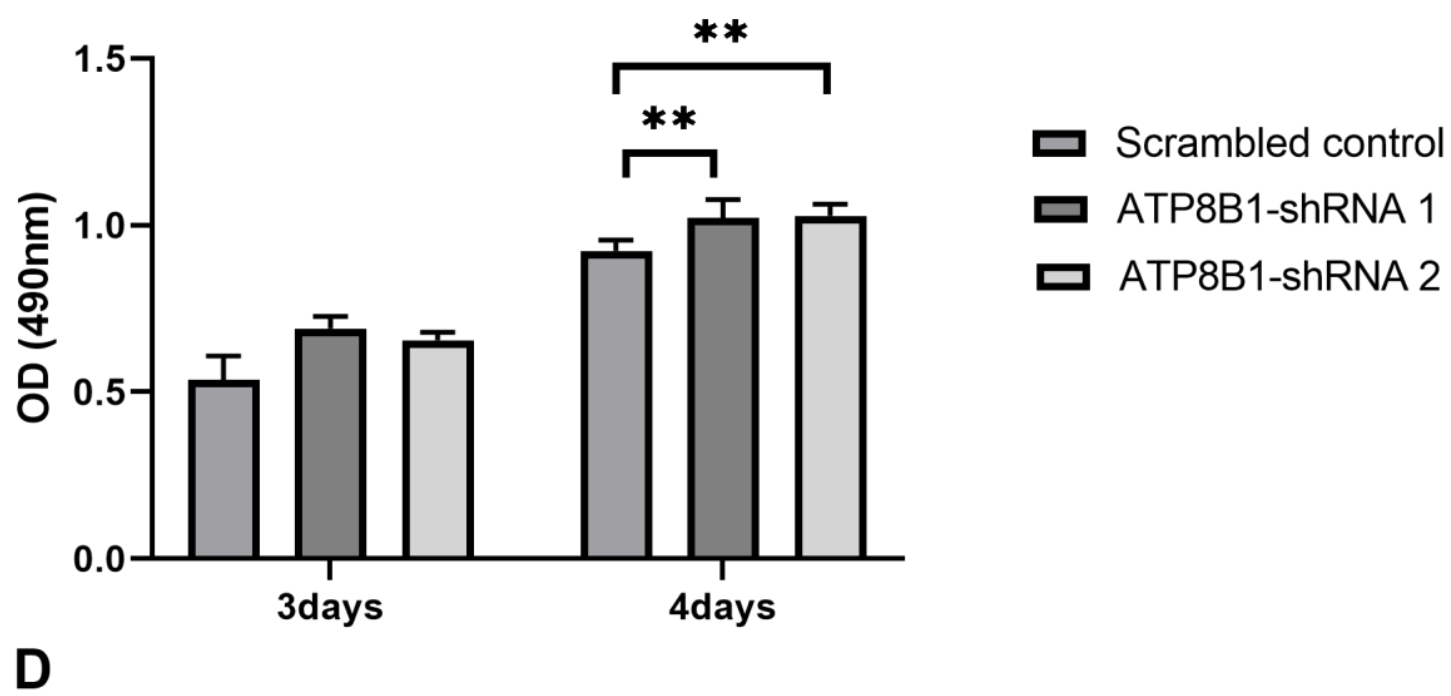

Figure 2: Downregulation of ATP8B1 gene using shRNA in HT29 cells

A: qRT-PCR results from three different clones of HT29 cells expressing reduced levels of ATP8B1 in comparison to cells with scrambled control. B: Western blot analysis of cells expressing downregulated levels of ATP8B1. C: HT29 cells expressing reduced ATP8B1 levels grow at a faster rate as reflected by the normalized cell index (Upper panel). Slope of these curves at three time points show significant increase in rate of cell growth D: Cell viability was analyzed in scrambled control and two selected colonies using MTS assay. There was significant increase in cell viability as measured on day 4

HT29 cells with CRISPR mediated downregulation of ATP8B1 gene

CRISPR/Cas9 based silencing strategy resulted in 51\% downregulation of ATP8B1 gene at transcript level (Figure 3A). At protein level, the observed difference from scrambled control was $66 \%$ (Figure 3B). These cells were found to show significantly increased rate of cell proliferation (up to 39\%) for $72 \mathrm{~h}$ (Figure 3C). We also did an end point MTS assay and found higher cell viability for the cells with downregulated ATP8B1 levels (Figure 3D). 
Figure 3
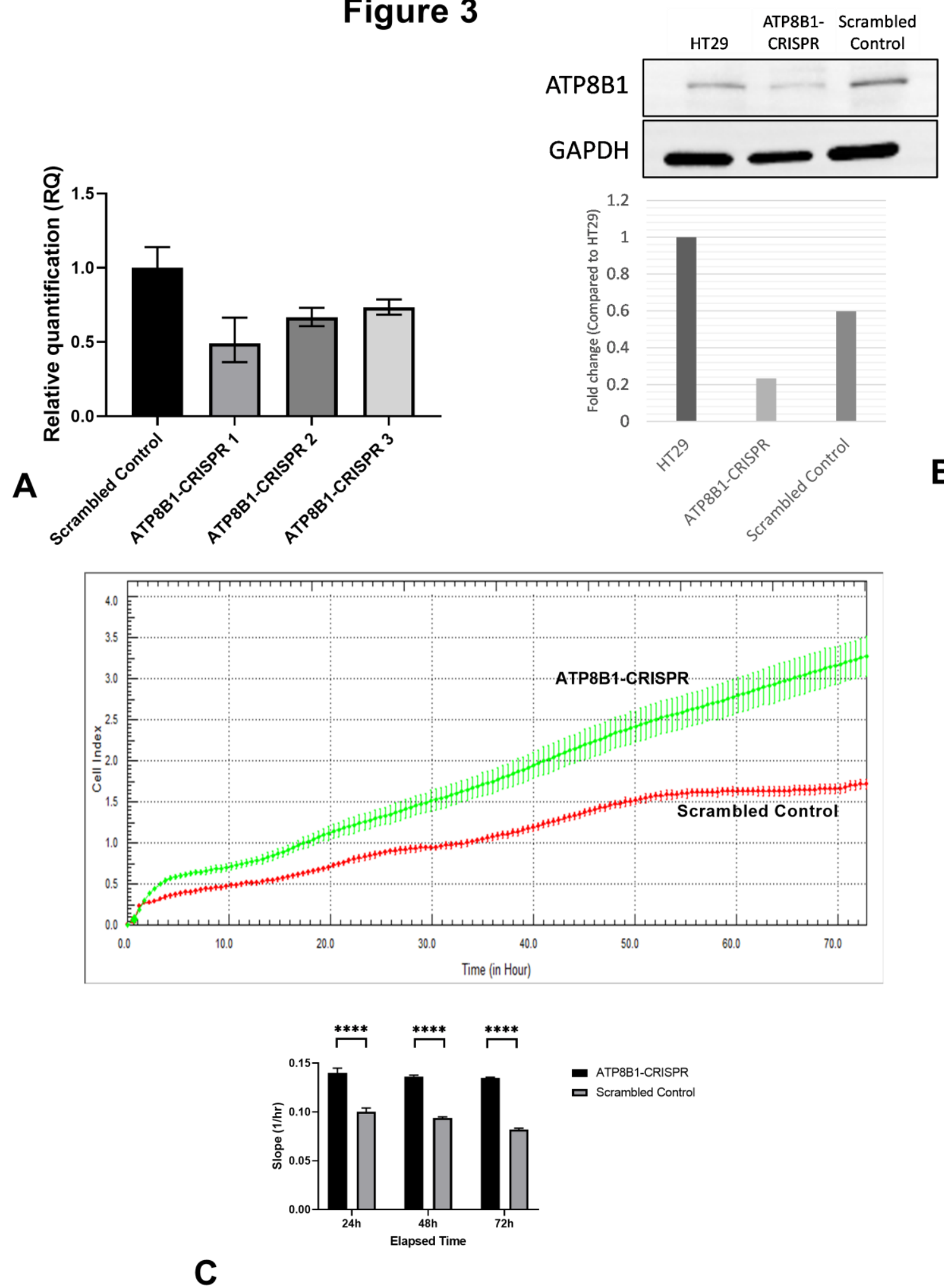


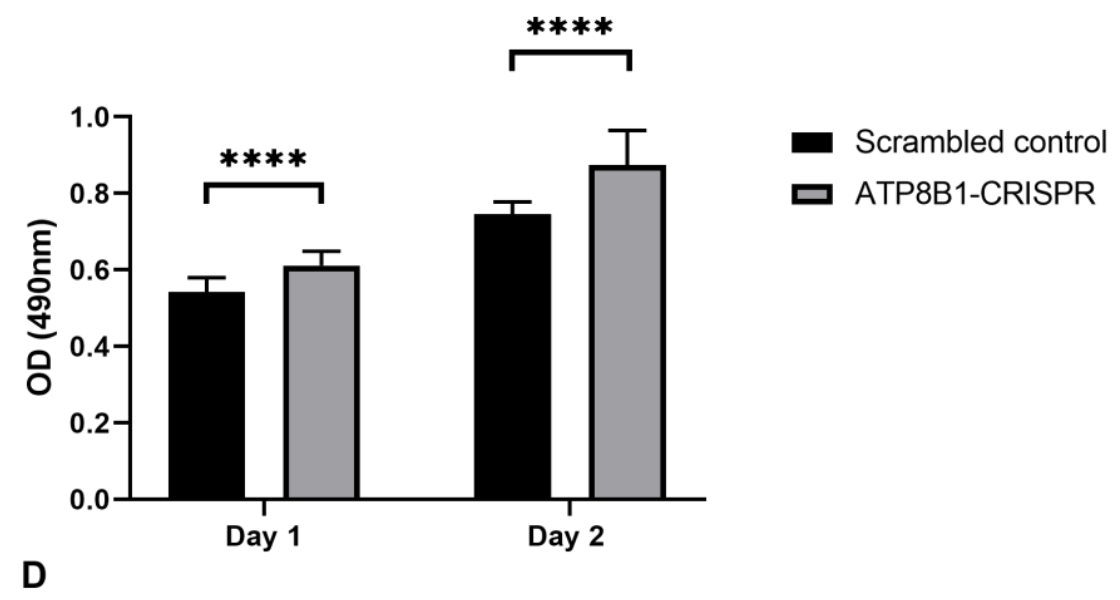

Figure 3: Downregulation of ATP8B1 gene through CRISPR/Cas9 in HT29 cells

A: Three different clones of CRISPR mediated knockdown of ATP8B1 were found to represent maximum downregulation as measured by qRT-PCR. B: Western blot analysis of ATP8B1 downregulated cells in comparison to untreated $\mathrm{Ht} 29$ cells and cells treated with scrambled control. C: xCELLigence based real time comparative analysis of rate of cell growth. The slope values represent significant difference at three time points. D: MTS assay representing significantly increased cell viability at Day 1 and 2 in CRISPR mediated ATP8B1 downregulated cells.

Slower cellular growth rate and less viability in ATP8B1 overexpressing cells

For overexpressing ATP8B1 gene, we selected single colonies of SW480 cells transduced with open reading frame packaged in lentiviral particles. We found increase in ATP8B1 expression at transcript ( $>1.5$ fold) and protein level ( $>2.5$ fold) (Figure 4A \& B). These cells exhibited decreased rate of cell proliferation as compared to the untransformed cells (Figure 4C). Further, lower cell viability as compared to the unmodified cells was also observed as determined by MTS assay (Figure 4D). 
Figure 4
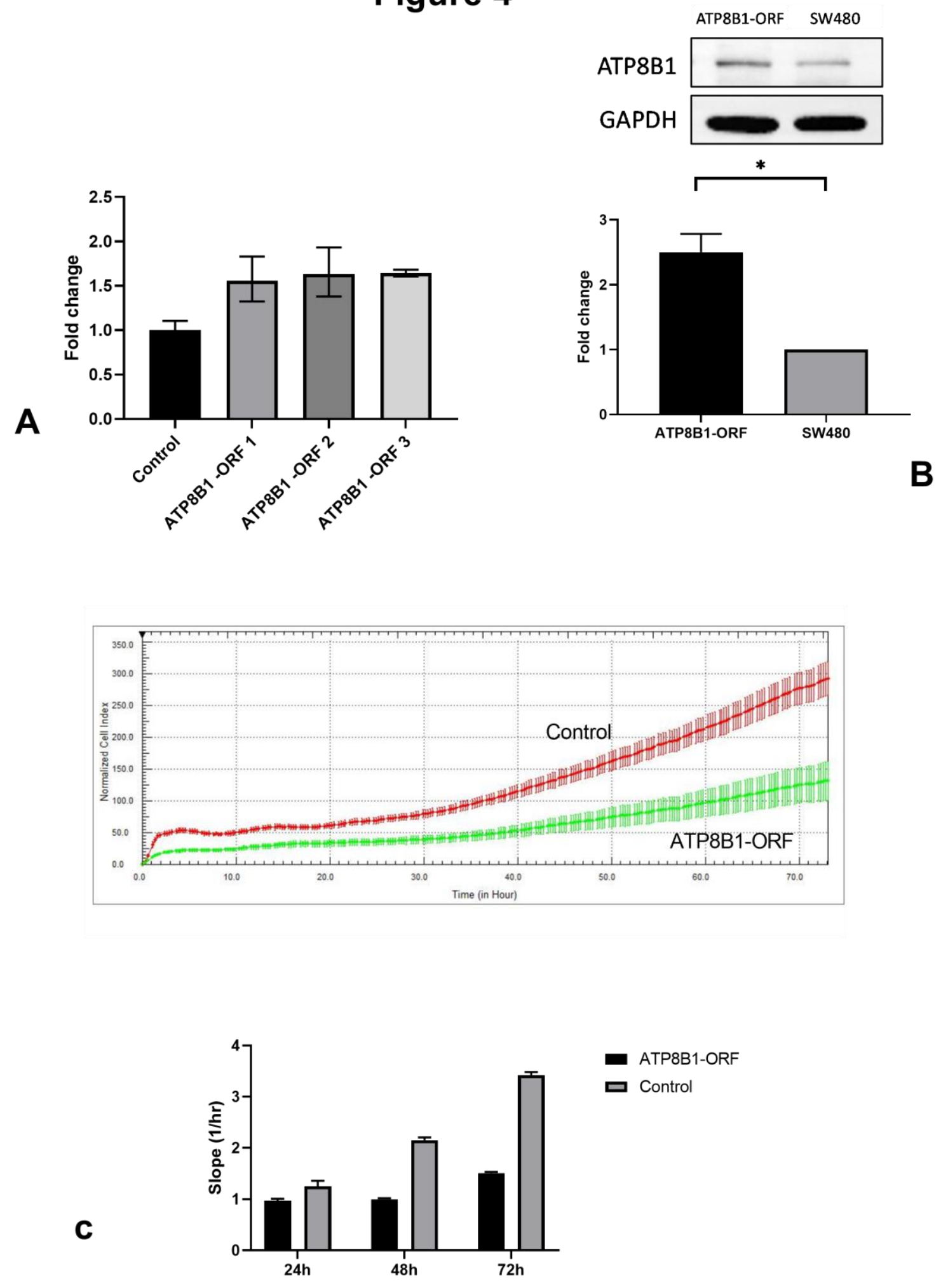


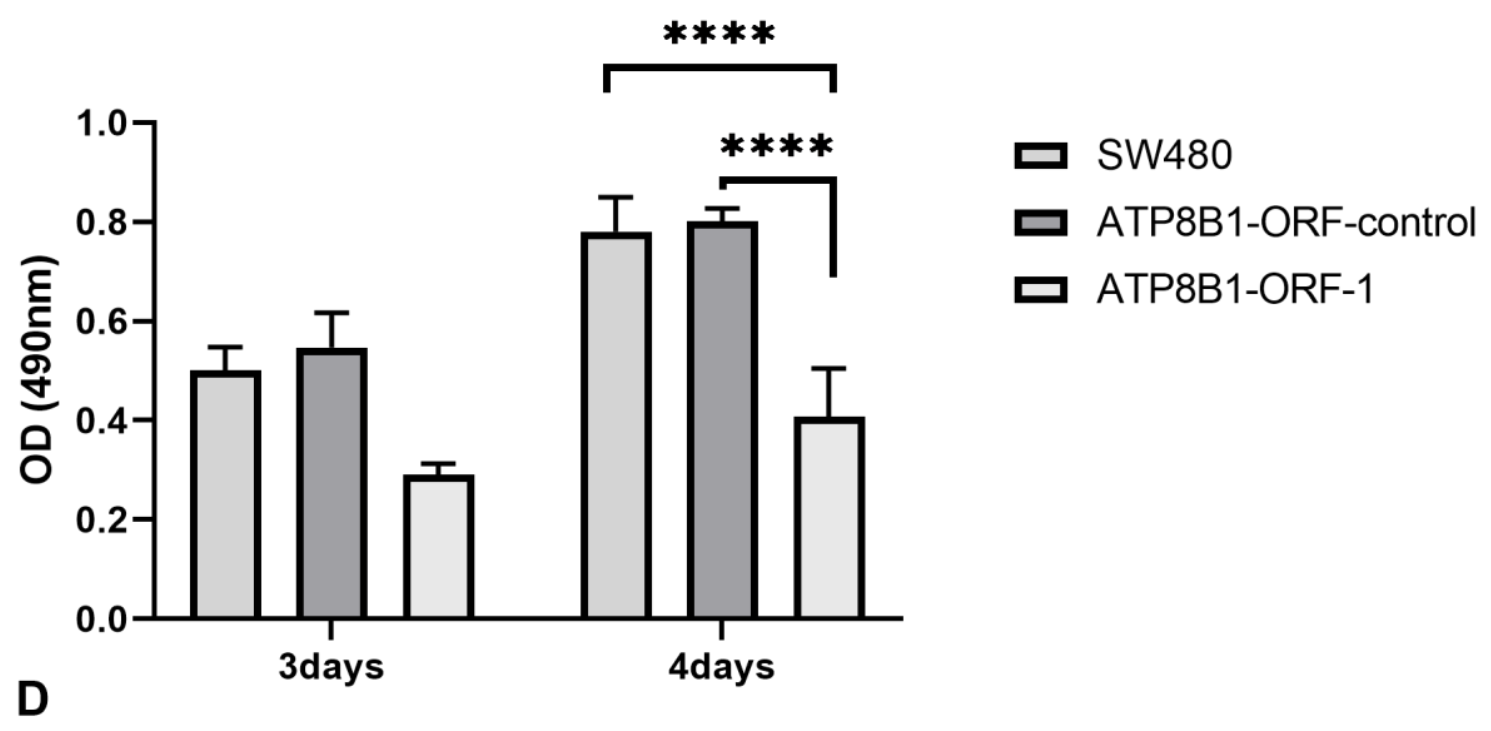

Figure 4: Overexpression of ATP8B1 gene in SW480 cells

A: Three clones of cells with overexpression of ATP8B1 cells were assayed using qRT-PCR. All three clones exhibit increased expression in comparison to SW480 cells B: Increased protein levels as compared to untreated SW480 cells were observed. C: Growth curves (upper panel) and calculated slope values upto 72 h. Bars represent values in triplicate. D: MTS assay show significantly reduced cell viability in ATP8B1 overexpressing cells.

ATP8B1 is not involved in the uptake or efflux of sphingolipids

Dysregulation of sphingolipid metabolism contribute to various pathological conditions including cancer [26]. P4-ATPases are known to transport phospholipids and glycosphingolipids. We studied whether ATP8B1 is involved in the transport of sphingolipids. HT29 cells treated with either Scrambled Control-shRNA, ATP8B1-shRNA or ATP8B1-CRISPR against ATP8B1 were incubated with $\mathrm{C}_{6}$-NBD ceramide for $3 \mathrm{~h}$ at 37 ${ }^{\circ} \mathrm{C}$ to determine the uptake of sphingolipids (NBD-Cer, Figure 5A upper band). Since ceramide is a precursor of other complex sphingolipids, it immediately gets converted to different sphingolipids inside the cells. Analysis of thin layer chromatogram showed the presence of two extra bands corresponding to glucosylceramides (NBD-GluCer, Figure 5A middle band) and sphingomyelin (NBD-SM, Figure 5A lower band) in each sample. Quantification of these bands showed no significant change in the levels of NBD-ceramide (Figure 5B) between Scrambled Control, ShRNA and CRISPR treated HT29 cells. However, there was a decrease of around $39 \%$ and $45 \%$ in the levels of NBD-GluCer in Sh RNA and CRISPR treated cells, respectively compared to Scrambled Control cells (Figure 
5C). Similarly, there was a decrease of around $23 \%$ and $30 \%$ in the levels of NBD-SM in ShRNA and CRISPR treated cells, respectively compared to Scrambled Control cells (Figure 5D). These data suggest that knockdown of ATP8B1 does not affect the uptake of NBD-ceramides but decreases the levels of NBD-glucosylceramides and NBD-sphingomyelin in the cells.

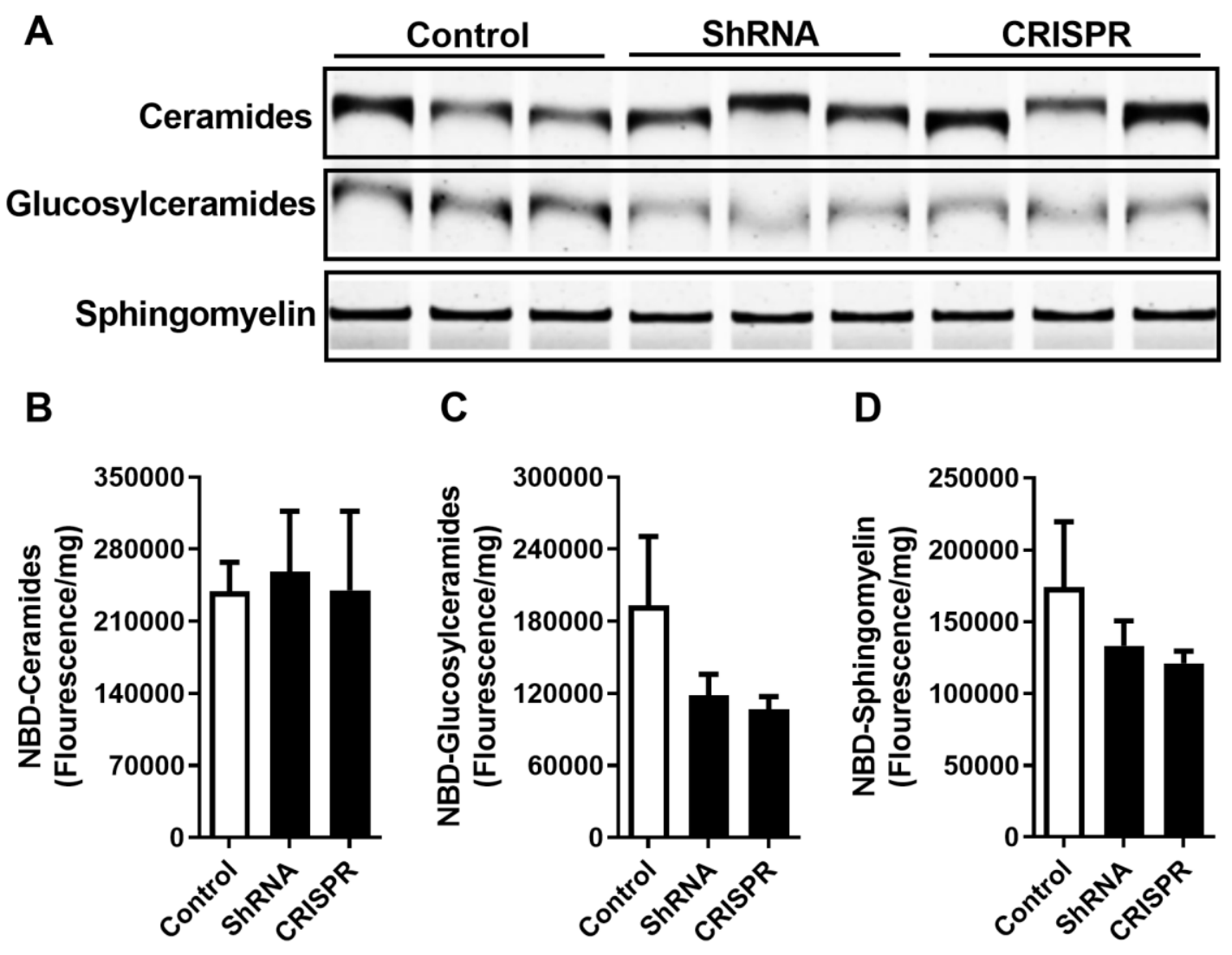

\section{Figure 5: Uptake of sphingolipids.}

HT29 cells grown in 24-well cell culture plates in triplicate were incubated with $2 \mu \mathrm{M}$ C6-NBD Ceramide in $10 \%$ FBS containing advanced DMEM at $37{ }^{\circ} \mathrm{C}$ for $3 \mathrm{~h}$ and washed three times with DMEM plus $0.1 \%$ BSA. A: Lipids from the cells were extracted and separated on thin-layer silica plates and visualized with the ChemiDoc Imaging System. B: Amounts of ceramides (NBD-Cer) taken up by the cells and subsequently converted to glucosylceramides (NBD-GluCer, Panel C) and sphingomyelin (NBD-SM, Panel D) were quantified by ImageJ software and data was plotted as Mean \pm SD.

The low cellular levels of NBD-glucosylceramides and NBD-sphingomyelin in ATP8B1 knockdown cells may be either due to increased efflux or reduced synthesis of these sphingolipids by the cells. To test these possibilities, we studied the efflux of these sphingolipids by the HT29 cells treated with either Scrambled Control, shRNA or CRISPR 
Cas9 against ATP8B1. Cells were labeled with $\mathrm{C}_{6}$-NBD ceramide for $3 \mathrm{~h}$ at $37{ }^{\circ} \mathrm{C}$ and then incubated with media containing $40 \mu \mathrm{g} / \mathrm{mL}$ human serum HDL to induce efflux (Figure 6A). Analysis of data again showed no change in the efflux of NBD-Cer (Figure 6B). Efflux of NBD-GluCer (Figure 6C) and NBD-SM (Figure 6D) was also low in cells treated with ShRNA (36\% and 30\%, respectively) and CRISPR (38\% and 24\%, respectively) against ATP8B1. These data again show that knockdown of ATP8B1 does not affect the efflux of NBD-ceramides but decreases the efflux of NBD-glucosylceramides and NBD-sphingomyelin from the cells.

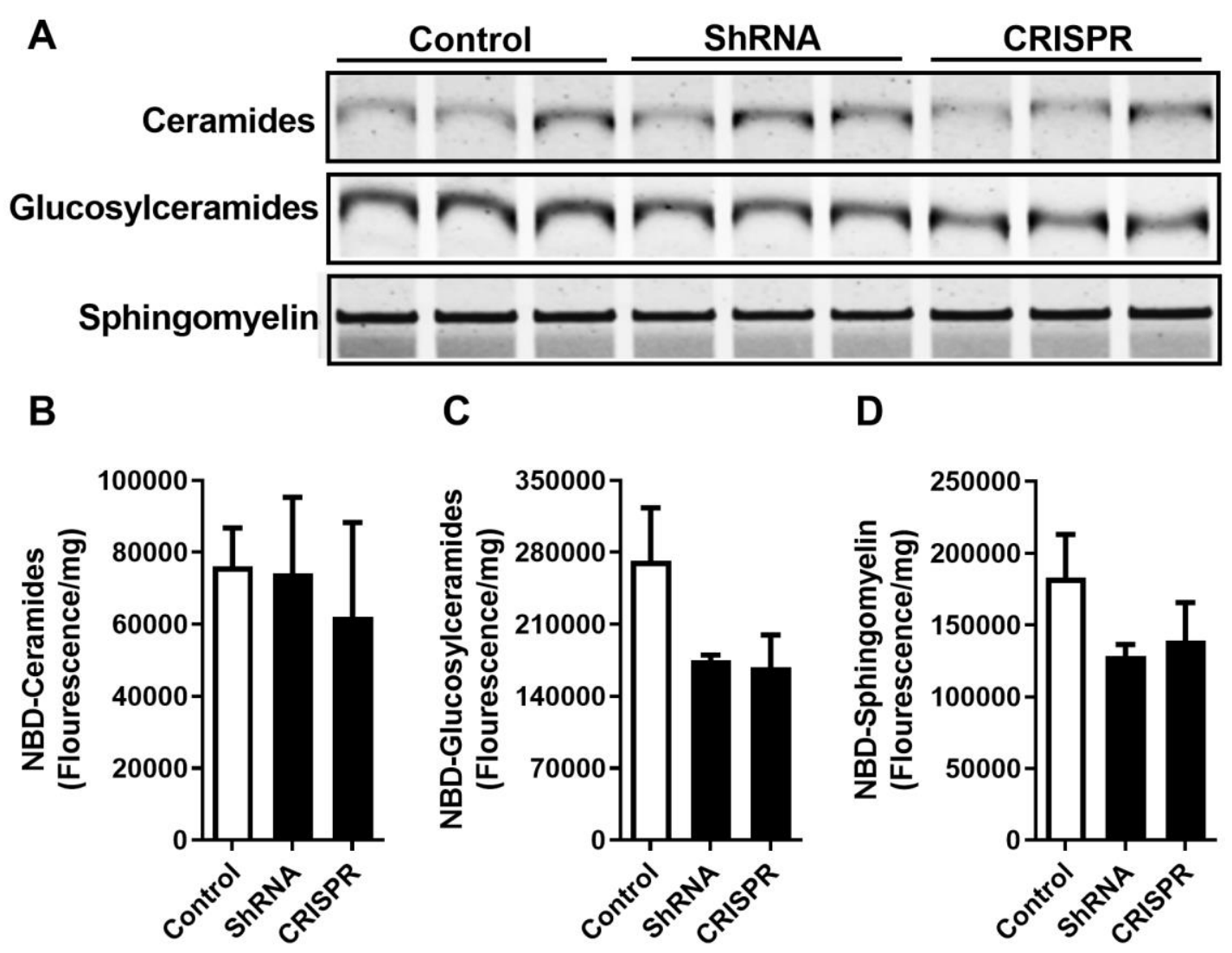

\section{Figure 6: Efflux of sphingolipids.}

HT29 cells grown in 24-well cell culture plates in triplicate were incubated with $2 \mu \mathrm{M}$ C6-NBD Ceramide in $10 \%$ FBS containing advanced DMEM at $37{ }^{\circ} \mathrm{C}$ for $3 \mathrm{~h}$ and washed three times with DMEM plus $0.1 \%$ BSA. The efflux was initiated by the addition of fresh media containing $40 \mu \mathrm{g} / \mathrm{mL}$ human serum HDL. Culture media were harvested after $4 \mathrm{~h}$ of incubation to determine efflux of sphingolipids. Lipids were extracted from the media and separated on thin-layer silica plates as described in Materials and Methods and visualized with the ChemiDoc Imaging System (Panel A). Amounts of ceramides (NBD-Cer, Panel B), glucosylceramides (NBD-GluCer, Panel C) and sphingomyelin (NBD-SM, Panel D) were quantified by ImageJ software and data was plotted as Mean \pm SD. 
Next, we also measured the levels of NBD-sphingolipids remaining inside the cells after efflux to HDL to determine whether these sphingolipids are being accumulated inside the cells (Figure 7A). However, our data showed that levels of NBD-Cer (Figure 7B), NBD-GluCer (Figure 7C), and NBD-SM (Figure 7D) remaining inside the cells was lower in ShRNA and CRISPR treated cells compared to Scrambled Control cells. Taken together, these data suggest that knockdown of ATP8B1 is not involved in the efflux of sphingolipids but may impact the synthesis of some of the complex sphingolipids from the precursor ceramides.

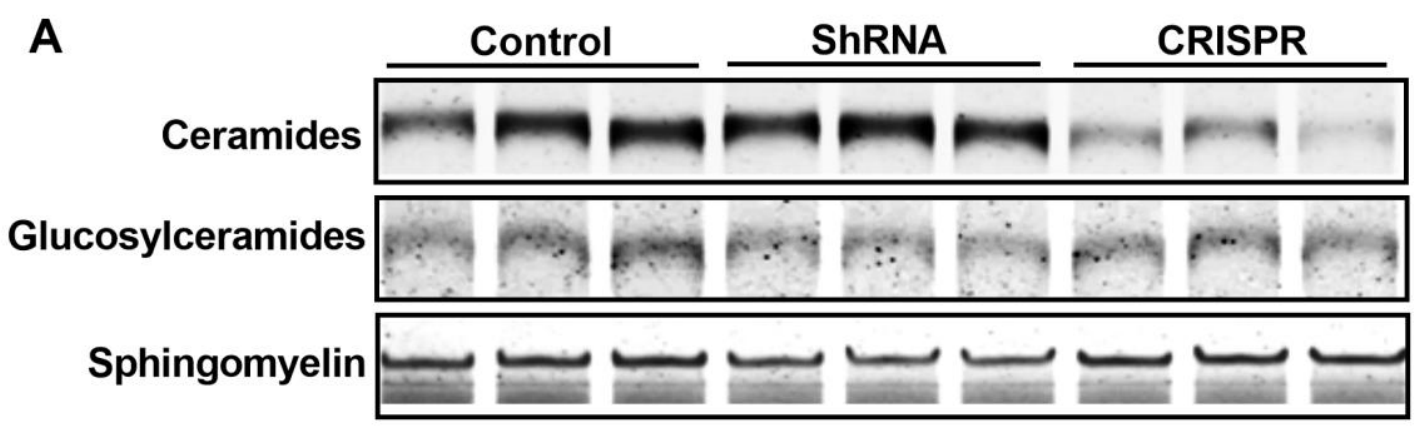

B

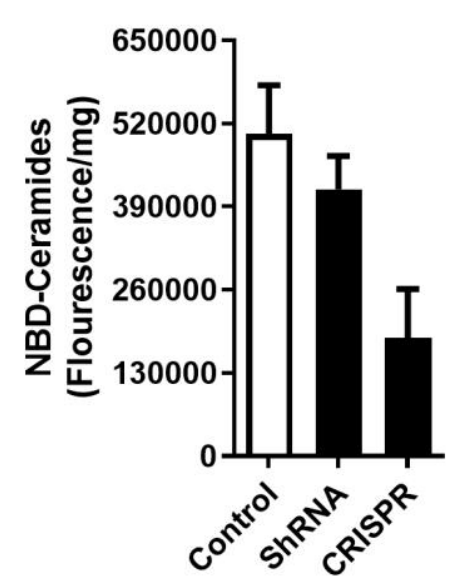

C

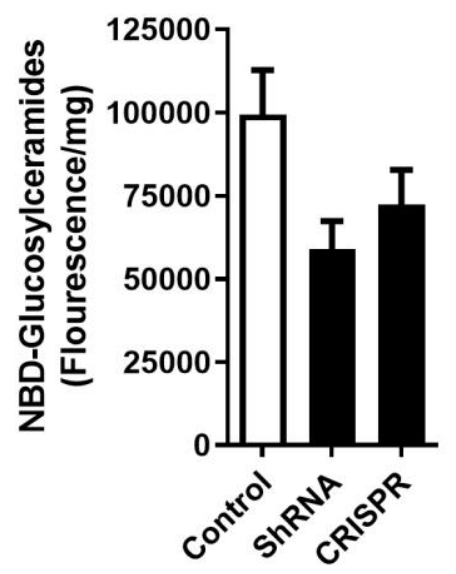

D

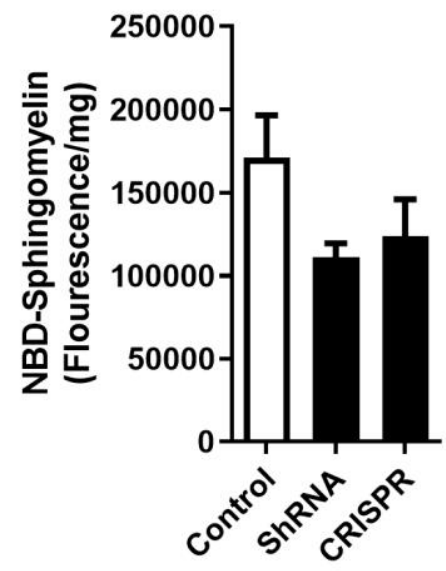

\section{Figure 7: Cellular sphingolipids.}

HT29 cells grown in 24-well cell culture plates in triplicate were incubated with $2 \mu \mathrm{M}$ C6-NBD Ceramide in $10 \%$ FBS containing advanced DMEM at $37{ }^{\circ} \mathrm{C}$ for $3 \mathrm{~h}$ and washed three times with DMEM plus $0.1 \%$ BSA. The efflux was initiated by the addition of fresh media containing $40 \mu \mathrm{g} / \mathrm{mL}$ human serum HDL. Culture media were harvested after $4 \mathrm{~h}$ of incubation to determine efflux of sphingolipids. Lipids were extracted from the cells and separated on thin-layer silica plates as described in Materials and Methods and visualized with the ChemiDoc Imaging System (Panel A). Amounts of ceramides (NBD-Cer, Panel B), glucosylceramides 
(NBD-GluCer, Panel C) and sphingomyelin (NBD-SM, Panel D) were quantified by ImageJ software and data was plotted as Mean \pm SD.

Effect of modulation of ATP8B1 could be through direct effect on CFTR gene

We performed computational analyses to study the effect of changing the expression levels of ATP8B1 gene. ATP8B1 is connected downstream with TMEM30A, TMEM30B, CFTR, SLC10A2, ABCB11, NR1H4 genes (Figure 8A). Our analysis suggest cystic fibrosis transport regulator (CFTR) gene to be possible mediator of the observed effect as it was found to be directly and proportionally effected by ATP8B1 expression levels (supplementary figures 5\&6). ATP8B1 being a lipid transporter could be associated with fatty acid metabolism. We analyzed network of all 117 genes involved in fatty acid metabolism that are connected with ATP8B1. NR1H4 is a possible gene connection that can play critical role in mediating the effect of ATP8B1. Complete network of ATP8B1 downstream genes with fatty acid metabolism is depicted in supplementary figure 7 . The regulation of ATP8B1 gene could be mediated through 33 miRNAs as listed in supplementary Table 1 . These regulatory miRNAs could be helpful in preparing strategies to increase gene expression levels through RNA activation. 


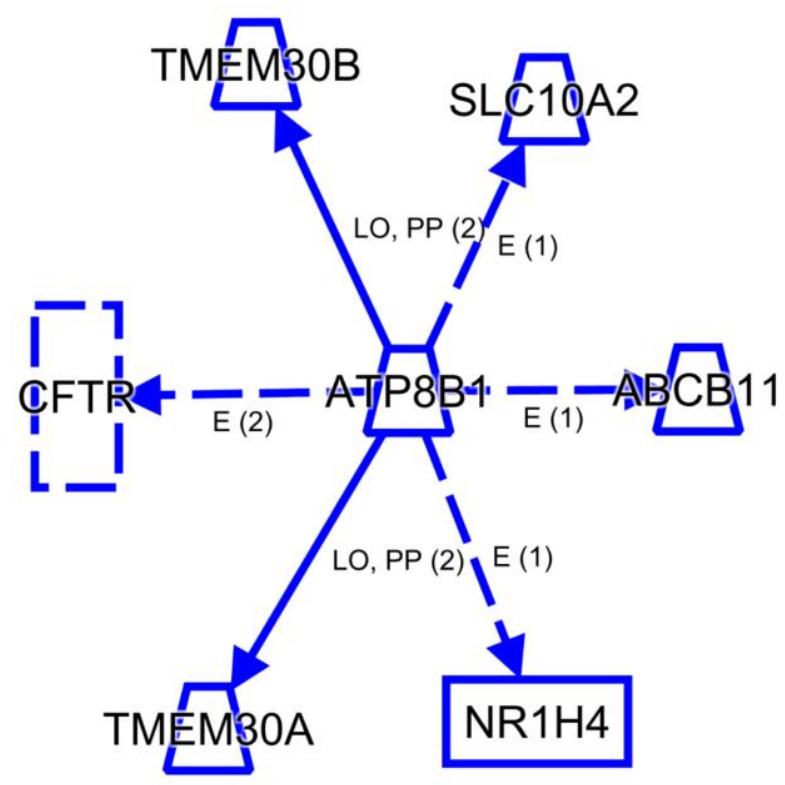

(C) 2000-2020 QIAGEN. All rights reserved.

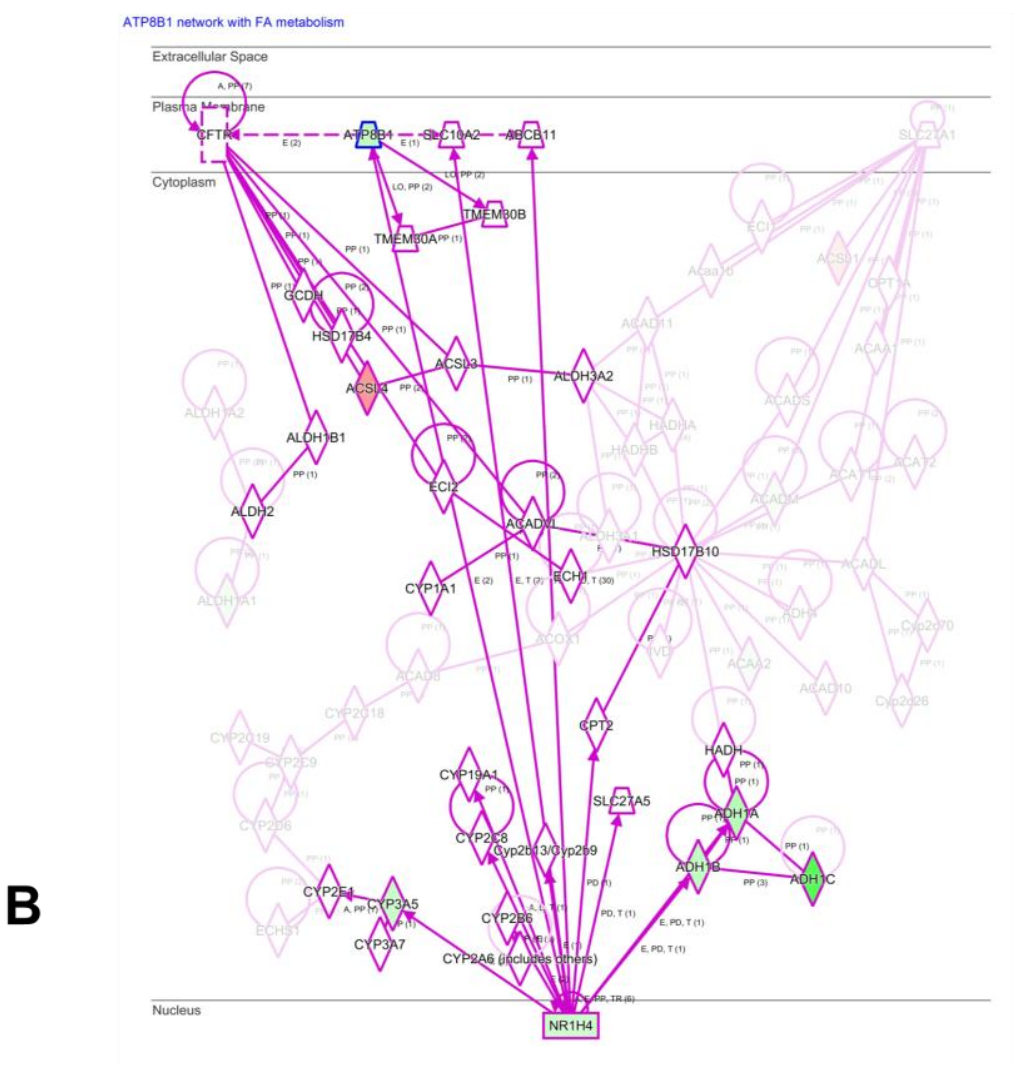

\section{Figure 8: ATP8B1 gene network}

A: Interacting genes of ATP8B1 were used to generate a network. Six genes were found to be downstream of ATP8B1. Ingenuity pathway analysis 'build pathway' function was used to build this network. B: Association of ATP8B1 network with fatty acid metabolism was mapped. The highlighted genes are directly associated with ATP8B1. Background shows other indirect interactions that could manifest the effect of altering ATP8B1 
expression levels. Nodes in green and red depict the down and up regulated state of these genes, respectively, as observed in our patient dataset. Gene Expression Omnibus (GEO) database Accession \# GSE50421.

Discussion

One of the well-known events in colorectal cancer progression is loss of heterozygosity of chromosome 18q [27]. Several important genes located on $18 \mathrm{q}$ locus were found to be associated with CRC. DCC, SMAD2 and SMAD4 genes located in these regions were studied as mediators of carcinogenesis. However, the observed frequency of alteration of these genes is not proportional to the loss of $18 \mathrm{q}$ in CRC. CABLES1 gene at the same locus was implicated as another tumor suppressor gene in colorectal cancer [28]. Loss of SMAD2 and 4 in CRC progression are better understood with the implication of TGF- $\beta$ signaling pathway. However, there is a pertinent need to unravel the molecular targets in this region to correlate and understand the conspicuous loss of $18 \mathrm{q}$ with progression of CRC. Identification and characterization of these targets will be helpful in developing diagnostic and therapeutic approaches. We previously reported novel genes associated with CRC that were significantly altered at genomic as well as transcriptomic level [23,24]. ATP8B1 is located at 18q21.31 and was found to be a significant target in cancer due to gene loss and reduced expression in tumor samples. In this study, we have attempted to characterize ATP8B1 gene as a tumor suppressor and provided evidence from indigenous patient studies as well as engineered cell lines.

From our previous study, we found ATP8B1 gene to be significantly downregulated in CRC patient samples [24]. A recent study based on the The Cancer Genome Atlas (TCGA) database, documents downregulation of ATP8B1 gene in colorectal cancer [29]. This study corroborates our results in characterization of ATP8B1 gene as a tumor suppressor. We selected CRC cell lines which could serve as surrogates for patient classes in CRC [20] and engineered them for decreased as well as increased levels of ATP8B1 gene. Cell lines exhibited various levels of ATP8B1 gene expression which represents the observed heterogeneity in gene expression based on different genetic landscape [30]. We selected relatively highest (HT29) and lowest (SW480) ATP8B1 expressing cells to observe a 
conspicuous difference in phenotype. We observed that protein levels are not reflecting the mRNA levels which support the notion of studying gene expression at different levels [31,32]. Our results suggest a connection between the altered ATP8B1 gene expression levels and the respective change in viability and rate of cell proliferation. This effect could be mediated through CFTR gene which is known to be involved in familial colorectal cancer syndrome [33]. Silencing of tumor suppressor gene (TSG) could generate cis- or trans- affects with local or global implications that may lead to the increased proliferation [34]. We employed complementary shRNA as well as CRISPR based strategies to confirm the specificity of the observed effect [35]. These engineered cell lines may serve as valuable tools for further dissecting the mechanism of ATP8B1 as a tumor suppressor.

ATP8B1 function as lipid transporter across the cell membrane. Sphingolipids are known to have therapeutic as well as prophylactic role in CRC possibly mediated by Wnt $\beta$-catenin signaling pathway [36]. Since altered sphingolipid transport could be a possible mechanism through which ATP8B1 exerts its effect, we analyzed the efflux as well uptake of sphingolipids in engineered cells. Our data suggest ATP8B1 is not involved in sphingolipid transport. However, we saw a decrease in the synthesis of sphingomyelin and glucosylceramides from the precursor ceramides given to the cells. Interestingly, our data show that decreased conversion of ceramides to these sphingolipids does not increase the levels of cellular ceramides. Since ceramides are toxic to cells and induce apoptosis[37], it is possible that in the absence of ATP8B1 ceramides may be converted to other sphingolipids to reduce apoptosis and promote cell proliferation. One of the possibilities is that ceramides may get converted to sphingosine-1-phosphate which is known to promote cell proliferation[38]. Higher levels of sphingosine-1-phosphate signaling have been associated with inflammation-associated CRC[39]. Furthermore, phospholipid homeostasis may also be disturbed due to loss of ATP8B1 leading to the progression of cancer [29].

This is first in vitro study describing the possible role of ATP8B1 gene as tumor suppressor. However, it is limited by providing preliminary indirect evidence based on gene expression related studies. Further studies are needed to establish the mechanistic aspects of ATP8B1 gene as a tumor suppressor. 
4. Materials and Methods

Cells and culture conditions

All Human colon cancer cell lines (HT29, HCT116, HCT8, DLD-1, SW480, SW620, RKO and Caco-2), Normal colon (CCD841) and human embryonic kidney cell lines (HEK293T) were purchased from American Type Culture Collection (ATCC, Manassas, VA, USA). Cells were grown in complete growth medium consisting of Advanced Dulbecco's Modified Eagle Medium (DMEM), $100 \mathrm{U} / \mathrm{ml}$ penicillin, $100 \mathrm{mg} / \mathrm{ml}$ streptomycin (Gibco, USA) and 1\% L-glutamine (Gibco, USA) supplemented with 10\% fetal bovine serum (Gibco, USA). All cells were incubated in a humidified incubator at $37^{\circ} \mathrm{C}$ with $5 \% \mathrm{CO}_{2}$.

\section{Patient data analysis}

Gene expression data from our previously published reports $[23,24]$ was used to measure the relative quantification of ATP8B1 in matched tumor-normal patient samples. Transcriptomics Analysis Console software (Thermofisher scientific, USA) was used to extract the data and further analysis was done using statistical software (GraphPad Prism version 8).

\section{Generation of stable ATP8B1 overexpressing SW480 cell line}

Preparation of viral particles: Open reading frame cloned in a vector with lentiviral packaging elements, C-terminal hemagglutinin (3X HA) tag and puromycin resistance gene was used for overexpression of ATP8B1 gene in SW480 cells. Vector construct was obtained from GeneCoepeia (Cat\#EX-I5663-Lv120, Rockville, MD, USA) for lentiviral particles preparation using lentiviral packaging kit (Cat\#TR30022, Origene, Rockville, MD, USA). HEK-293T cells were transfected with 1 $1 \mu \mathrm{g}$ ATP8B1 ORF plasmid and transfection control plasmid in a 6 well plate using MegaTran reagent (Cat\#TT210002, Origene, Rockville, MD, USA). The culture medium was changed after $12-18 \mathrm{~h}$ incubation. The viral supernatant in the culture medium was collected at 48 and 72 hours post transfection and centrifuged for 5 minutes at $3000 \mathrm{rpm}$, then passed through 0.45 micron filter to remove cellular debris. The viral titer at this step was approximately $10^{6}-10^{7} \mathrm{TU} / \mathrm{ml}$ (Transduction units per $\mathrm{ml}$ ) and the viral particles were used immediately for cell transduction or stored at $-80{ }^{\circ} \mathrm{C}$ freezer. 
Cell Transduction: For the generation of stable cell lines, $5 \times 10^{4}$ SW 480 cells were plated in 24 well plate in $0.5 \mathrm{ml}$ complete growth medium supplemented with $5 \%$ FBS. On the day of transduction, $70 \%$ confluent cells were infected with $100 \%, 70 \%, 50 \%, 30 \%, 20 \%$ and $10 \%$ viral supernatant along with $10 \mathrm{ug} / \mathrm{ml}$ polybrene (Sigma-Aldrich, Taufkirchen, Germany). Cells were selected with $1 \mu \mathrm{g} / \mathrm{ml}$ puromycin antibiotic (Gibco) added to the growth medium 48 hours after the transduction. The culture medium was replaced every 2 days to remove dead cells. After 21 days of selection the cells were assayed for ATP8B1 gene overexpression using quantitative real time polymerase chain reaction (qRT-PCR) and immunoblotting.

\section{Generation of stable ATP8B1 knockdown HT29 cell line with CRISPR/Cas9}

CRISPR human gene knockdown kit was obtained from GeneCoepeia (Cat\# CCPCTR01-1-CG12, Rockville, MD, USA). The kit had three guide RNA (gRNA) targeting ATP8B1 gene and one scramble control. HT29 Cells were cultured in 6 well plate and transfected with $2.5 \mu \mathrm{g}$ plasmid using Lipofectamine3000 (Thermo Fisher Scientific) following the company protocol. Cells were selected and maintained in a complete growth medium with $400 \mu \mathrm{g} / \mathrm{ml} \mathrm{G418} \mathrm{Geneticin} \mathrm{antibiotic} \mathrm{(Gibco).} \mathrm{Cells} \mathrm{were} \mathrm{screened} \mathrm{for} \mathrm{ATP8B1}$ gene expression using quantitative real time polymerase chain reaction (qRT-PCR) and immunoblotting. One colony of selected ATP8B1 knockdown and scrambled control cells was used for subsequent experiments.

\section{Generation of stable ATP8B1 knockdown HT29 cell line with shRNA}

A set of four short-hairpin RNA (shRNA) targeting the human ATP8B1 gene and scrambled control of shRNA were obtained from (GeneCopoeia, Rockville, MD, USA). Lipofectamine3000 (Thermo Fisher Scientific, USA) with 2.5 $\mu \mathrm{g}$ of ATP8B1 DNA plasmid was used for transfection of HT-29 cells. $2 \mu \mathrm{g} / \mathrm{ml}$ puromycin (Gibco) in the complete growth medium was used for selection of knockdown cells and screened for ATP8B1 using quantitative real time polymerase chain reaction (qRT-PCR) and immunoblotting. 
Total RNA was extracted from modified human colon cancer cell lines (ATP8B1-ORF, SW480, ATP8B1-shRNA, HT29, ATP8B1-CRISPR) using PureLink RNA mini kit (Cat\#12183025, Thermo Fisher Scientific,USA). $2.5 \mu \mathrm{g}$ of RNA was reverse transcribed for cDNA synthesis using High-Capacity cDNA Reverse Transcription Kit (Applied Biosystems, Thermo Fisher Scientific). qRT-PCR was performed by using TaqMan universal PCR master mix and the QuantStudio 6 Flex Real-Time PCR System (Thermo Fisher Scientific, Inc) according to the manufacturer's instructions. The gene expression was analyzed using TaqMan ATP8B1 gene (Cat\# Hs00900656_m1, Thermo Fisher Scientific, USA). Eukaryotic 18S rRNA was used as endogenous control gene. All reactions were performed in triplicate and the qRT-PCR data was analyzed by using the relative quantitative (RQ) method $\left(2^{-\Delta \Delta C t}\right)$ through Expression Suite software version 1.1 (Thermo Fisher Scientific, USA). All experiments are repeated at least twice.

\section{Real time cell proliferation and migration assays}

Cell proliferation assay: To measure cell proliferation and migration in real-time without the incorporation of labels xCELLigence System real time cell analyzer-dual purpose (RTCA-DP) from ACEA biosciences (San Diego, USA) was used as described earlier[40]. This system measures electrical impedance across interdigitated microelectrodes integrated on the bottom of tissue culture special plates (E-plates 16) procured from ACEA biosciences. For cell proliferation assay 20,000 cells from 'ATP8B1-shRNA', 'ATP8B1-CRISPR', 'ATP8B1-ORF,' and their respective controls, were seeded on E-plate16 in $100 \mu 1$ of complete growth media. The E-Plates were incubated at $37^{\circ} \mathrm{C}$ with $5 \% \mathrm{CO}_{2}$ and monitored on the RTCA system (ACEA biosciences, USA) at 30-minute time intervals for up to $72 \mathrm{hr}$. For data analysis, the baseline Cell Index (CI) was calculated by subtracting the CI for a well containing cells and CI of a well with only culture media. To facilitate the statistical evaluation of the results, at least three repeats of each experimental condition were performed as recommended in the technical manual of xCELLigence.

Cell migration assay: 20,000 cells were seeded in each well of the UC (upper chamber) of CIM plate-16 in serum-free media from ATP8B1-SHRNA/HT29, ATP8B1-CRISPR/HT29, ATP8B1-ORF/SW480 and their respective controls. Media with 0\%, 10\% FBS was added to 
each well of the LC (lower camber), cell migration was monitored for $24 \mathrm{hrs}$. The experiment was repeated at least 2 times and slope values of the growth curve were plotted using in-built software and later analyzed on Graph Pad prism version 8.

\section{Protein isolation and western blotting}

'ATP8B1-shRNA', 'ATP8B1-CRISPR' \& 'ATP8B1-ORF' and their respective control cells were lysed with NP40 buffer (Invitrogen, Paisley, UK) containing protease inhibitor cocktail (Sigma-Aldrich, Taufkirchen, Germany). The protein lysate was incubated on ice for 30 minutes and centrifuged at 13,000 rpm for 10 minutes and the supernatant was collected. Protein concentrations were determined by Qubit protein assay kit (Thermo Fisher Scientific). $30 \mu \mathrm{g}$ of whole cell lysate was mixed with $4 \mathrm{X}$ Laemmli buffer (Bio-Rad) and loaded onto ready-made gel 4-20\% Mini-PROTEAN® TGX ${ }^{\mathrm{TM}}$ Precast Protein Gels (Bio-Rad). The gel was subjected to electrophoresis at 100V for approximately 90 minutes and transferred overnight at $5 \mathrm{~V}$ to polyvinyl PVDF membranes using semidry transfer cell (Bio-Rad). The membranes were blocked using 5\% Bovine Serum Albumin (MILLIPORE, Germany) in TBST (Tris Buffer Saline Tween) for 1 hour with shaking at room temperature followed by the incubation of the membrane with 1:2000 of ATP8B1 rabbit primary antibody (Cat\#orb41661, biorbyt) in 5\% BSA with gentle shaking overnight $(\mathrm{O} / \mathrm{N})$ at $4^{\circ} \mathrm{C}$. The blots were incubated with the 1:1000 appropriate Goat Anti-Rabbit IgG (H+L)-HRP Conjugate antibody (Bio-Rad), GAPDH was used as housekeeping protein (Cat\#orb500708 biorbyt). The signals were detected with Chemiluminiscent HRP Substrate (Bio-Rad) on Imagedoc gel documentation system (BioRad).

End point cell viability assay

Cell proliferation was assessed using a tetrazolium compound [3-(4,5-dimethylthiazol-2-yl)-5-(3-carboxymethoxyphenyl)-2-(4-sulfophenyl)-2H-tetrazoliu m, inner salt; MTS] kit (\#G5421, CellTiter 96® Aqueous Non-Radioactive Cell Proliferation

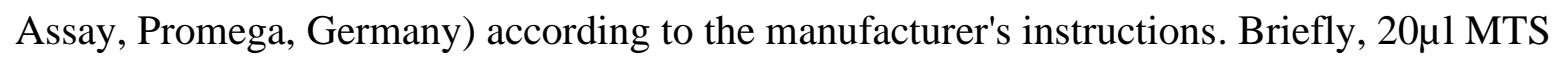
solution was added into each well of the 96 well assay plate containing 2000 cells in complete culture medium and incubated for $4 \mathrm{~h}$. The absorbance at $490 \mathrm{~nm}$ was recorded 
using a plate reader (Spectra MR, Dynex Technologies, Denkendorf, Germany). Results are presented as means $( \pm \mathrm{SD})$ obtained from triplicate wells. MTS solution in medium not exposed to cells was used as blank.

\section{Uptake and efflux of sphingolipids}

For uptake experiments, HT29 cells treated with either Scrambled Control, shRNA or CRISPR/Cas9 against ATP8B1 and grown in 24-well cell culture plates (catalog no. 142475, Nunc $^{\mathrm{TM}}$ ) in triplicate were incubated with $2 \mu \mathrm{M} \mathrm{C}_{6}$-NBD Ceramide (catalog no. 6224, Setareh Biotech) in 10\% FBS (Gibco) containing advanced DMEM (Gibco) at $37{ }^{\circ} \mathrm{C}$ for $3 \mathrm{~h}$ and washed three times with DMEM plus $0.1 \%$ BSA. Lipids from the cells were extracted by isopropanol and separated on thin-layer silica plates (catalog no. 44931, Analtech, Inc.) using a $\mathrm{CHCl}_{3}: \mathrm{CH}_{3} \mathrm{OH}: \mathrm{C}_{6} \mathrm{H}_{5} \mathrm{CH}_{3}: \mathrm{NH}_{4} \mathrm{OH}: \mathrm{H}_{2} \mathrm{O}$ (40:40:20:0.4:1.6, ratios by volume) solvent system [41] and visualized with the ChemiDoc Imaging System (BioRad). Bands were quantified by ImageJ software (U.S. National Institutes of Health). Proteins were measured in the cells by Pierce ${ }^{\mathrm{TM}}$ Coomassie Plus (Bradford) assay reagent (catalog no. 23238, ThermoFisher Scientific) and used to normalize the fluorescent density in each band. To study efflux of sphingolipids, HT29 cells treated with either Scrambled Control, shRNA or CRISPR Cas9 against ATP8B1 were incubated with $2 \mu \mathrm{M} \mathrm{C}_{6}$-NBD Ceramide in $10 \%$ FBS containing advanced DMEM at $37{ }^{\circ} \mathrm{C}$ for $3 \mathrm{~h}$ and washed three times with DMEM plus $0.1 \%$ BSA. The efflux was initiated by the addition of fresh media containing $40 \mu \mathrm{g} / \mathrm{mL}$ human serum HDL (catalog no. MBS173147, MyBioSource). Culture media were harvested after 4 $\mathrm{h}$ of incubation and centrifuged at $580 \mathrm{~g}$ for $15 \mathrm{~min}$ at $4{ }^{\circ} \mathrm{C}$ to pellet-detached cells. Lipids in the media were extracted [42], separated on TLC, and visualized with the ChemiDoc Imaging System as described above. Lipids were also extracted from the cells and separated on thin-layer silica plates as described before.

\section{Statistical and computational analyses}

GraphPad Prism version 8 was used to carry out all statistical analyses. For generating ATP8B1 networks, Ingenuity analysis pathway (Qiagen Biosciences) was used. Molecular 
predictor analysis tool was used to predict the effect of modulation of gene expression on targets downstream of ATP8B1.

\section{Conclusions}

Tumor suppressor gene (ATP8B1) located on chromosome $18 \mathrm{q}$ could be responsible in progression of colorectal cancer. Knocking down of this gene causes increased rate of cell proliferation and reduced cell death suggesting its role as a tumor suppressor. Increasing the expression of this gene in colorectal cancer cells slowed down their growth and increased cell death. These evidence suggest the role of ATP8B1 as a tumor suppressor gene.

\section{Supplementary Materials:8 Figures and 1 Table}

Author Contributions: Conceptualization, MAA; methodology, SA, AA, MHA, EH, DA and JI.; software, MAA; validation, SA, AA, MHA, EH, DA and JI; formal analysis, MAA, DA and JI; resources, MAA and SM; data curation, MAA.; writing-original draft preparation, MAA, SA, AA, DA and JI.; writing-review and editing, SM; supervision, MAA; project administration, MAA; funding acquisition, MAA and SM. All authors have read and agreed to the published version of the manuscript.

Funding: This study was supported by a grant RC16/192 from King Abdullah International medical Research Center (KAIMRC) awarded to MAA and SM.

Acknowledgments: We would like to acknowledge the support from Research operations (Dr. Barrak Al Somaie) and Research office (Dr. Majed AlJeraisy) for successful completion of the project. Help and support from Dr. Yaser basmaeili in carrying out MTS and xCELLigence based assays is duly acknowledged.

Conflicts of Interest: The authors declare no conflict of interest. The funders had no role in the design of the study; in the collection, analyses, or interpretation of data; in the writing of the manuscript, or in the decision to publish the results.

\section{References}

1. Marmol, I.; Sanchez-de-Diego, C.; Pradilla Dieste, A.; Cerrada, E.; Rodriguez Yoldi, M.J. Colorectal Carcinoma: A General Overview and Future Perspectives in Colorectal Cancer. Int J Mol Sci 2017, 18, doi:10.3390/ijms18010197.

2. Worthley, D.L.; Leggett, B.A. Colorectal cancer: molecular features and clinical opportunities. Clin Biochem Rev 2010, 31, 31-38.

3. Yatime, L.; Buch-Pedersen, M.J.; Musgaard, M.; Morth, J.P.; Lund Winther, A.M.; Pedersen, B.P.; Olesen, C.; Andersen, J.P.; Vilsen, B.; Schiott, B., et al. P-type ATPases as drug targets: tools for medicine and science. Biochimica et biophysica acta 2009, 1787, 207-220.

4. Kampen, K.R. Membrane proteins: the key players of a cancer cell. J Membr Bio/ 2011, 242, 69-74, doi:10.1007/s00232-011-9381-7.

5. Madjd, Z.; Pinder, S.E.; Paish, C.; Ellis, I.O.; Carmichael, J.; Durrant, L.G. Loss of CD59 expression in breast tumours correlates with poor survival. J Pathol 2003, 200, 633-639, doi:10.1002/path.1357.

6. Xu, C.; Jung, M.; Burkhardt, M.; Stephan, C.; Schnorr, D.; Loening, S.; Jung, K.; Dietel, M.; Kristiansen, G. Increased CD59 protein expression predicts a PSA relapse in patients after radical prostatectomy. Prostate 2005, 62, 224-232, doi:10.1002/pros.20134. 
7. Fan, L.; Li, A.; Li, W.; Cai, P.; Yang, B.; Zhang, M.; Gu, Y.; Shu, Y.; Sun, Y.; Shen, Y., et al. Novel role of Sarco/endoplasmic reticulum calcium ATPase 2 in development of colorectal cancer and its regulation by F36, a curcumin analog. Biomed Pharmacother 2014, 68, 1141-1148, doi:10.1016/j.biopha.2014.10.014.

8. Geyik, E.; Igci, Y.Z.; Pala, E.; Suner, A.; Borazan, E.; Bozgeyik, I.; Bayraktar, E.; Bayraktar, R.; Ergun, S.; Cakmak, E.A., et al. Investigation of the association between ATP2B4 and ATP5B genes with colorectal cancer. Gene 2014, 540, 178-182, doi:10.1016/j.gene.2014.02.050.

9. Gou, W.F.; Niu, Z.F.; Zhao, S.; Takano, Y.; Zheng, H.C. Aberrant SERCA3 expression during the colorectal adenoma-adenocarcinoma sequence. Oncology reports 2014, 31, 232-240, doi:10.3892/or.2013.2837.

10. Kuhlbrandt, W. Biology, structure and mechanism of P-type ATPases. Nat Rev Mol Cell Biol 2004, 5, 282-295, doi:10.1038/nrm1354.

11. Jasmine, F.; Rahaman, R.; Dodsworth, C.; Roy, S.; Paul, R.; Raza, M.; Paul-Brutus, R.; Kamal, M.; Ahsan, H.; Kibriya, M.G. A genome-wide study of cytogenetic changes in colorectal cancer using SNP microarrays: opportunities for future personalized treatment. PLoS One 2012, 7, e31968, doi:10.1371/journal.pone.0031968.

12. Miyoshi, N.; Ishii, H.; Mimori, K.; Tanaka, F.; Nagai, K.; Uemura, M.; Sekimoto, M.; Doki, Y.; Mori, M. ATP11A is a novel predictive marker for metachronous metastasis of colorectal cancer. Oncol Rep 2010, 23, 505-510.

13. Deng, B.C.; Lv, S.; Cui, W.; Zhao, R.; Lu, X.; Wu, J.; Liu, P. Novel ATP8B1 mutation in an adult male with progressive familial intrahepatic cholestasis. World J Gastroenterol 2012, 18, 6504-6509, doi:10.3748/wjg.v18.i44.6504.

14. Copeland, E.; Renault, N.; Renault, M.; Dyack, S.; Bulman, D.E.; Bedard, K.; Otley, A.; Magee, F.; Acott, P.; Greer, W.L. Novel splice-site mutation in ATP8B1 results in atypical progressive familial intrahepatic cholestasis type 1. J Gastroenterol Hepatol 2013, 28, 560-564, doi:10.1111/j.1440-1746.2012.07290.x.

15. van der Woerd, W.L.; van Haaften-Visser, D.Y.; van de Graaf, S.F.; Ferec, C.; Masson, E.; Stapelbroek, J.M.; Bugert, P.; Witt, H.; Houwen, R.H. Mutational analysis of ATP8B1 in patients with chronic pancreatitis. PLoS One 2013, 8, e80553, doi:10.1371/journal.pone.0080553.

16. van der Woerd, W.L.; Mulder, J.; Pagani, F.; Beuers, U.; Houwen, R.H.; van de Graaf, S.F. Analysis of aberrant pre-messenger RNA splicing resulting from mutations in ATP8B1 and efficient in vitro rescue by adapted U1 small nuclear RNA. Hepatology 2015, 61, 1382-1391, doi:10.1002/hep.27620.

17. Cai, S.Y.; Gautam, S.; Nguyen, T.; Soroka, C.J.; Rahner, C.; Boyer, J.L. ATP8B1 deficiency disrupts the bile canalicular membrane bilayer structure in hepatocytes, but FXR expression and activity are maintained. Gastroenterology 2009, 136, 1060-1069, doi:10.1053/j.gastro.2008.10.025.

18. Deng, B.C.; Lv, S.; Cui, W.; Zhao, R.; Lu, X.; Wu, J.; Liu, P. Novel ATP8B1 mutation in an adult male with progressive familial intrahepatic cholestasis. World J Gastroenterol 2012, 18, 6504-6509, doi:10.3748/wjg.v18.i44.6504.

19. Srivastava, A. Progressive familial intrahepatic cholestasis. J Clin Exp Hepatol 2014, 4, 25-36, doi:10.1016/j.jceh.2013.10.005. 
20. Mouradov, D.; Sloggett, C.; Jorissen, R.N.; Love, C.G.; Li, S.; Burgess, A.W.; Arango, D.; Strausberg, R.L.; Buchanan, D.; Wormald, S., et al. Colorectal cancer cell lines are representative models of the main molecular subtypes of primary cancer. Cancer Res 2014, 74, 3238-3247, doi:10.1158/0008-5472.CAN-14-0013.

21. Van Allen, E.M.; Wagle, N.; Sucker, A.; Treacy, D.J.; Johannessen, C.M.; Goetz, E.M.; Place, C.S.; Taylor-Weiner, A.; Whittaker, S.; Kryukov, G.V., et al. The genetic landscape of clinical resistance to RAF inhibition in metastatic melanoma. Cancer Discov 2014, 4, 94-109, doi:10.1158/2159-8290.CD-13-0617.

22. Murphy, S.J.; Hart, S.N.; Lima, J.F.; Kipp, B.R.; Klebig, M.; Winters, J.L.; Szabo, C.; Zhang, L.; Eckloff, B.W.; Petersen, G.M., et al. Genetic alterations associated with progression from pancreatic intraepithelial neoplasia to invasive pancreatic tumor. Gastroenterology 2013, 145, 1098-1109 e1091, doi:10.1053/j.gastro.2013.07.049.

23. Eldai, H.; Periyasamy, S.; Al Qarni, S.; Al Rodayyan, M.; Mustafa, S.M.; Deeb, A.; Al Sheikh, E.; Khan, M.A.; Johani, M.; Yousef, Z. Novel genes associated with colorectal cancer are revealed by high resolution cytogenetic analysis in a patient specific manner. PLoS One 2013, 8, e76251.

24. Aziz, M.A.; Periyasamy, S.; Al Yousef, Z.; AlAbdulkarim, I.; Al Otaibi, M.; Alfahed, A.; Alasiri, $G$. Integrated exon level expression analysis of driver genes explain their role in colorectal cancer. PLoS One 2014, 9, e110134, doi:10.1371/journal.pone.0110134.

25. The Protein Atlas.

26. Roland, B.P.; Naito, T.; Best, J.T.; Arnaiz-Yepez, C.; Takatsu, H.; Yu, R.J.; Shin, H.W.; Graham, T.R. Yeast and human P4-ATPases transport glycosphingolipids using conserved structural motifs. J Biol Chem 2019, 294, 1794-1806, doi:10.1074/jbc.RA118.005876.

27. Jen, J.; Kim, H.; Piantadosi, S.; Liu, Z.F.; Levitt, R.C.; Sistonen, P.; Kinzler, K.W.; Vogelstein, B.; Hamilton, S.R. Allelic loss of chromosome $18 q$ and prognosis in colorectal cancer. $N$ Engl J Med 1994, 331, 213-221, doi:10.1056/NEJM199407283310401.

28. Park, D.Y.; Sakamoto, H.; Kirley, S.D.; Ogino, S.; Kawasaki, T.; Kwon, E.; Mino-Kenudson, M.; Lauwers, G.Y.; Chung, D.C.; Rueda, B.R., et al. The Cables gene on chromosome $18 q$ is silenced by promoter hypermethylation and allelic loss in human colorectal cancer. Am J Pathol 2007, 171, 1509-1519, doi:10.2353/ajpath.2007.070331.

29. Deng, L.; Niu, G.M.; Ren, J.; Ke, C.W. Identification of ATP8B1 as a Tumor Suppressor Gene for Colorectal Cancer and Its Involvement in Phospholipid Homeostasis. Biomed Res Int 2020, 2020, 2015648, doi:10.1155/2020/2015648.

30. Sveen, A.; Bruun, J.; Eide, P.W.; Eilertsen, I.A.; Ramirez, L.; Murumagi, A.; Arjama, M.; Danielsen, S.A.; Kryeziu, K.; Elez, E., et al. Colorectal Cancer Consensus Molecular Subtypes Translated to Preclinical Models Uncover Potentially Targetable Cancer Cell Dependencies. Clin Cancer Res 2018, 24, 794-806, doi:10.1158/1078-0432.CCR-17-1234.

31. Liu, Y.; Beyer, A.; Aebersold, R. On the Dependency of Cellular Protein Levels on mRNA Abundance. Cell 2016, 165, 535-550, doi:10.1016/j.cell.2016.03.014.

32. Aziz, M.A.; Yousef, Z.; Saleh, A.M.; Mohammad, S.; Al Knawy, B. Towards personalized medicine of colorectal cancer. Crit Rev Oncol Hematol 2017, 118, 70-78, doi:10.1016/j.critrevonc.2017.08.007. 
33. Scott, P.; Anderson, K.; Singhania, M.; Cormier, R. Cystic Fibrosis, CFTR, and Colorectal Cancer. Int J Mol Sci 2020, 21, doi:10.3390/ijms21082891.

34. Jia, P.; Zhao, Z. Characterization of Tumor-Suppressor Gene Inactivation Events in 33 Cancer Types. Cell Rep 2019, 26, 496-506 e493, doi:10.1016/j.celrep.2018.12.066.

35. Boettcher, M.; McManus, M.T. Choosing the Right Tool for the Job: RNAi, TALEN, or CRISPR. Mol Cell 2015, 58, 575-585, doi:10.1016/j.molcel.2015.04.028.

36. Garcia-Barros, M.; Coant, N.; Truman, J.P.; Snider, A.J.; Hannun, Y.A. Sphingolipids in colon cancer. Biochim Biophys Acta 2014, 1841, 773-782, doi:10.1016/j.bbalip.2013.09.007.

37. Guenther, G.G.; Edinger, A.L. A new take on ceramide: starving cells by cutting off the nutrient supply. Cell Cycle 2009, 8, 1122-1126, doi:10.4161/cc.8.8.8161.

38. Nagahashi, M.; Tsuchida, J.; Moro, K.; Hasegawa, M.; Tatsuda, K.; Woelfel, I.A.; Takabe, K.; Wakai, T. High levels of sphingolipids in human breast cancer. J Surg Res 2016, 204, 435-444, doi:10.1016/j.jss.2016.05.022.

39. Nguyen, A.V.; Wu, Y.Y.; Lin, E.Y. STAT3 and sphingosine-1-phosphate in inflammation-associated colorectal cancer. World J Gastroenterol 2014, 20, 10279-10287, doi:10.3748/wjg.v20.i30.10279.

40. Al Mahri, S.; Al Ghamdi, A.; Akiel, M.; Al Aujan, M.; Mohammad, S.; Aziz, M.A. Free fatty acids receptors 2 and 3 control cell proliferation by regulating cellular glucose uptake. World J Gastrointest Oncol 2020, 12, 514-525, doi:10.4251/wjgo.v12.i5.514.

41. Iqbal, J.; Walsh, M.T.; Hammad, S.M.; Cuchel, M.; Tarugi, P.; Hegele, R.A.; Davidson, N.O.; Rader, D.J.; Klein, R.L.; Hussain, M.M. Microsomal Triglyceride Transfer Protein Transfers and Determines Plasma Concentrations of Ceramide and Sphingomyelin but Not Glycosylceramide. J Biol Chem 2015, 290, 25863-25875, doi:10.1074/jbc.M115.659110.

42. Bligh, E.G.; Dyer, W.J. A rapid method of total lipid extraction and purification. Can J Biochem Physiol 1959, 37, 911-917, doi:10.1139/o59-099. 